CLINICAL STUDY

\title{
Phenotypic diversity in patients with lipodystrophy associated with LMNA mutations
}

\author{
Patricia B Mory, Felipe Crispim, Maria Beatriz S Freire ${ }^{1}$, João Eduardo N Salles ${ }^{2}$, Cynthia M Valério ${ }^{3}$, \\ Amelio F Godoy-Matos ${ }^{3}$, Sérgio A Dib and Regina S Moisés \\ Division of Endocrinology, Paulista School of Medicine, Universidade Federal de São Paulo, Rua Pedro de Toledo, 781 - 12 andar, 04039-032 São Paulo, \\ São Paulo, Brazil, ${ }^{1}$ Faculdade de Medicina de Jundiaí, Jundiaí, São Paulo, Brazil, ${ }^{2}$ Faculdade de Ciências Médicas, Santa Casa de São Paulo, São Paulo, \\ São Paulo, Brazil and ${ }^{3}$ Instituto Estadual de Diabetes e Endocrinologia, Rio de Janeiro, Rio de Janeiro, Brazil \\ (Correspondence should be addressed to R S Moisés; Email: rmoises@unifesp.br)
}

\begin{abstract}
Objective: Mutations in LMNA have been linked to diverse disorders called laminopathies, which display heterogeneous phenotypes and include diseases affecting muscles, axonal neurons, progeroid syndromes, and lipodystrophies. Among the lipodystrophies, LMNA mutations have been reported most frequently in patients with familial partial lipodystrophy (FPLD) of the Dunnigan variety; however, phenotypic heterogeneity in the pattern of body fat loss has been observed. In this study, we searched for LMNA mutations in patients with various forms of lipodystrophy.

Design and methods: We studied 21 unrelated individuals with lipodystrophy. Subjects underwent a complete clinical evaluation and were classified as typical FPLD $(n=12)$, atypical partial lipodystrophy $(n=7)$, or generalized lipodystrophy $(n=2)$. Molecular analysis of $L M N A$ gene, analysis of body fat by dual-energy X-ray absorptiometry, and biochemical measurements were performed.

Results: All patients with typical FPLD were found to carry LMNA mutations: seven patients harbored the heterozygous p.R482W (c.1444C > T), two patients harbored the p.R482Q (c.1445G >A), and two individuals harbored the novel heterozygous variant p.N466D (c.1396A $>$ G), all in exon 8. Also, a homozygous p.R584H (c.1751 G>A) mutation in exon 11 was found. Among patients with atypical partial lipodystrophy, two of them were found to have LMNA mutations: a novel heterozygous p.R $582 \mathrm{C}$ variation (c.1744 C>T) in exon 11 and a heterozygous substitution p.R349W (c.1045C $>$ T) in exon 6. Among patients with generalized lipodystrophy, only one harbored LMNA mutation, a heterozygous p.T10I (c.29C > T) in exon 1.

Conclusions: We have identified LMNA mutations in phenotypically diverse lipodystrophies. Also, our study broadens the spectrum of LMNA mutations in lipodystrophy.
\end{abstract}

European Journal of Endocrinology 167 423-431

\section{Introduction}

Lamin A/C gene (LMNA), which encodes type A lamins, is mapped to chromosome 1q21-22 and contains 12 exons (1). Through alternative splicing, this gene produces two major protein isoforms, lamin $\mathrm{A}$ and lamin $\mathrm{C}$, that polymerize with type B lamins to form the nuclear lamina, a complex meshwork of proteins underlying the inner nuclear membrane. Besides the main function of providing structural scaffolding for the cell nucleus, the nuclear lamina also has a role in chromatin organization, connection between nucleus and cytoplasm, gene transcription, and mitosis (2). Mutations in LMNA have been linked to diverse disorders called laminopathies, which display heterogeneous phenotypes and include diseases affecting muscle tissues, axonal neurons, rare progeroid syndromes, and lipodystrophies $(3,4,5,6,7,8)$.
Lipodystrophies are a group of clinically heterogeneous disorders characterized by localized or generalized loss of adipose tissue. Metabolic complications such as insulin resistance, impaired glucose tolerance, dyslipidemia, and hepatic steatosis are generally present in affected patients and their severity is determined by the extent of fat loss $(9,10)$. Among the lipodystrophies, LMNA mutations have been reported most frequently in patients with familial partial lipodystrophy (FPLD) of the Dunnigan variety, an autosomal dominant condition characterized by gradual loss of adipose tissue from the extremities and trunk starting at the puberty. However, phenotypic heterogeneity in the pattern of body fat loss has been observed among the laminopathies $(11,12,13,14,15,16,17)$. Therefore, in this study, we searched for LMNA mutations in patients with various forms of lipodystrophy. 


\section{Materials and methods}

The study population comprised 21 unrelated individuals (20 females and one male, aged 17- to 64-years old) with lipodystrophy. Subjects underwent a complete clinical evaluation and were classified as typical FPLD $(n=12)$, atypical partial lipodystrophy $(n=7)$, or generalized lipodystrophy $(n=2)$ based on the clinical criteria. Typical FPLD was characterized by progressive postpubertal loss of adipose tissue in limbs, abdomen, and trunk giving rise to appearance of increased muscularity. These patients may develop an excess of fat in face, neck, and supraclavicular region. The phenotype was classified as atypical partial lipodystrophy when this classical phenotype was not accomplished: patients demonstrated a less severe loss of adipose tissue, with the lipoatrophy being more evident in the legs. Patients with generalized lipodystrophy noted loss of fat during childhood or adolescence. Individuals receiving antiretroviral therapy were excluded.

Blood was collected after a 12-h overnight fast for DNA extraction and analysis of plasma glucose and lipoproteins.

Diagnosis of diabetes mellitus was based on fasting plasma glucose $\geq 126 \mathrm{mg} / \mathrm{dl}$ or use of antidiabetic agents (18). Dyslipidemia was diagnosed when total cholesterol was $\geq 200 \mathrm{mg} / \mathrm{dl}$, triglycerides was $\geq 150 \mathrm{mg} / \mathrm{dl}$, or HDL-cholesterol level was $<40 \mathrm{mg} / \mathrm{dl}$ in men and $<50 \mathrm{mg} / \mathrm{dl}$ in women or treatment with lipid-lowering drugs (19). Hypertension was defined as blood pressure $\geq 140 / 90 \mathrm{mmHg}$ or on antihypertensive medication (20). One hundred chromosomes from 50 unrelated nondiabetic individuals (fasting plasma glucose $<100 \mathrm{mg} / \mathrm{dl}$ ) were used as controls.

\section{Molecular analysis of LMNA gene}

DNA was extracted from peripheral blood leukocytes using a commercial kit (Gentra Puregene Blood Kit; Qiagen). Exons 1-12 and the intron-exon boundaries of LMNA gene were amplified by PCR using 14 pairs of primers. The PCR products were directly sequenced with the use of Big Dye Terminator Cycle Sequencing Reaction Kit version 3.1 and analyzed on an ABI Prism 3100 Genetic Analyzer (Applied Biosystems, Foster City, CA, USA). We used in silico bioinformatic tools, Polyphen (21) and SIFT (22), to predict the potential pathogenic effect of novel missense variants.

\section{Analysis of total and segmental body fat}

Dual-energy X-ray absorptiometry (DEXA) was used to evaluate whole-body and regional fat with the Hologic device (model QDR-4500A; Hologic, Inc., Bedford, MA, USA). Reference values were determined in healthy subjects matched for sex, age, and BMI.
Each female patient was matched with a subject based on sex, age (within 3 years), and BMI (within $3 \mathrm{~kg} / \mathrm{m}^{2}$ ). For the male patient, four subjects were matched based on sex, age (within 1 year), and BMI (within $3 \mathrm{~kg} / \mathrm{m}^{2}$ ).

\section{Biochemical measurements}

Plasma glucose was determined by the glucose-oxidase method and insulin by chemoluminescence assay. Cholesterol contents of lipoprotein fractions and triglycerides were measured enzymatically. Leptin and adiponectin concentrations were measured by ELISA (Linco Research, St Charles, MI, USA). This study was approved by the Ethics Committee of Escola Paulista de Medicina, Universidade Federal de São Paulo, and all participants were informed about the aims of the study and gave their written consent.
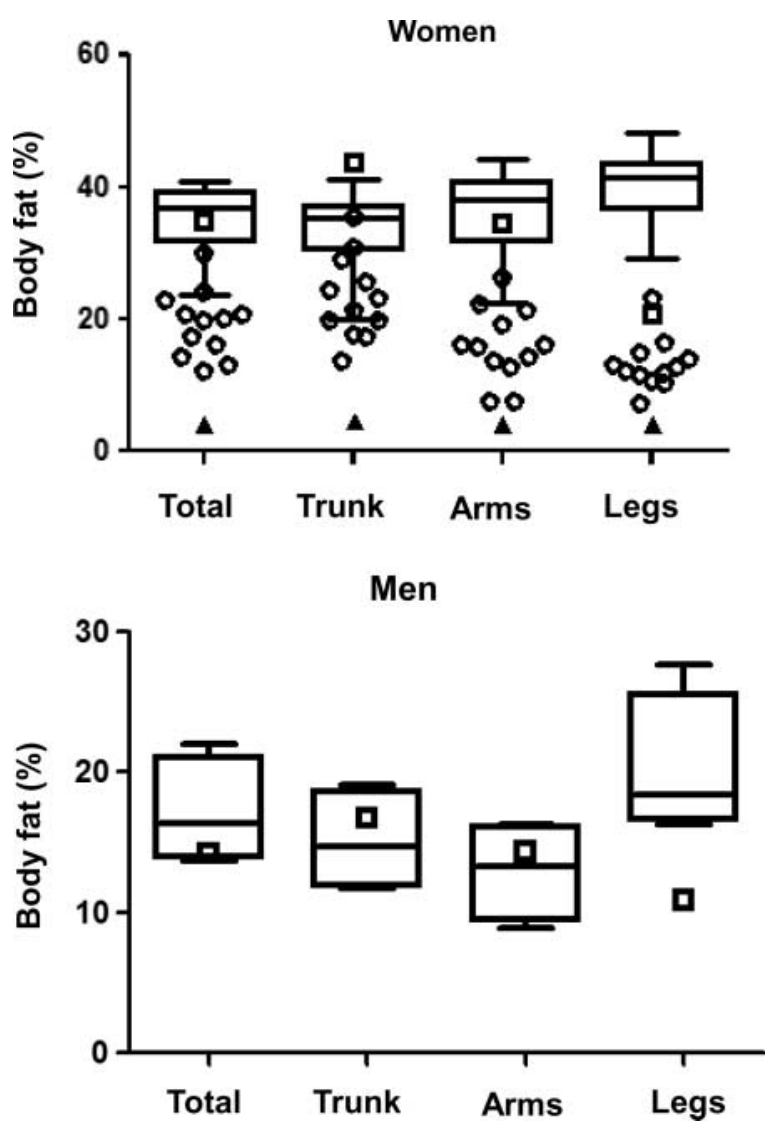

Figure 1 Whole and regional body fat in lipodystrophic patients carrying $L M N A$ mutations. The box displays the median and interquartile range (25th-75th percentile) and the whiskers display the 10th and 90th values for age-, sex-, and BMI-matched control individuals. Phenotypes of patients are symbolized as follows: open circle, typical FPLD; open square, atypical partial lipodystrophy; and closed triangle, generalized lipodystrophy. 


\section{Results}

Among the 21 patients with lipodystrophy who were screened, LMNA mutations were found in 15 of them. Whole-body and regional fat measurements showed that, compared with normal age-, sex-, and BMImatched controls, women with typical FPLD had reduced percentage of fat in arms and legs, while the patient P13 with atypical partial lipodystrophy had reduced fat only in the legs. As expected, the patient with generalized lipodystrophy had markedly reduced percentage of fat on all sites examined. The male patient P14 showed reduced percentage of fat only in the legs (Fig. 1).

\section{Typical FPLD}

Twelve patients (P1-P12), all female, aged 17-64 years, and from unrelated families with FPLD were studied. All of them were found to carry LMNA mutations: seven patients harbored the heterozygous p.R482W (c. $1444 \mathrm{C}>\mathrm{T}$ ) variation in exon 8, two patients harbored the p.R482Q (c.1445G $>$ A) variation, two individuals (patients $\mathrm{P} 1$ and $\mathrm{P} 11$ ) harbored the novel heterozygous variant p.N466D (c.1396A $>$ G) also in exon 8, and one patient (P12) harbored the homozygous p.R584H (c.1751G $>$ A) variation in exon 11. The novel variant p.N466D was not seen in 100 normal chromosomes and was predicted to be possibly damaging by PolyPhen and tolerated by SIFT.

Patient P1, a 22-year-old female, had insulin-requiring diabetes diagnosed at age 17 . She also had hypertension and hypertriglyceridemia since age 18. Physical examination showed the typical fat loss mentioned earlier (Fig. 2). Acanthosis nigricans was present in the cervical region and axillae. Hypertrophy of the calves was also observed. Her mother, also a carrier of the p.N466D variant, had diabetes diagnosed at age 24 complicated with coronaropathy, nephropathy, and neuropathy. She died at the age of 44 years due to myocardial infarction. Patient P11 is a 19-year-old female, apparently not related to $\mathrm{P} 1$, with diabetes and hypertension diagnosed at age 18. Loss of subcutaneous fat was first noticed at age 10. Physical examination showed lipoatrophy of the limbs and trunk and prominent muscles in her legs. Her father, a mutation carrier, had dyslipidemia and impaired fasting glucose. Patient P12 is a 26-year-old female with moderate decrease in subcutaneous fat on limbs and trunk, prominent veins in legs, and acanthosis nigricans in the axillae (Fig. 3). The only plasma lipid abnormality detected was low HDL-cholesterol (46 mg/dl). Hypertension was not present. An oral glucose tolerance test was performed and showed normal glucose tolerance. A homozygous p.R584H (c.1751 G>A) in exon 11 was found. Both of her parents, first-degree cousins, were heterozygous for this mutation. Her father apparently did not have the phenotypic abnormalities suggestive of lipodystrophy, but a clinical evaluation could not be performed. His lipid profile showed mild dyslipidemia (HDL-cholesterol $35 \mathrm{mg} / \mathrm{dl}$, LDL-cholesterol $142 \mathrm{mg} / \mathrm{dl}$, and triglycerides $58 \mathrm{mg} / \mathrm{dl}$ ) with normal fasting glucose. Clinical examination of her mother showed no evidence of lipoatrophy or acanthosis nigricans. Vitiligo lesions were present in the face, trunk, and limbs (Fig. 3). Dyslipidemia was present (total cholesterol $285 \mathrm{mg} / \mathrm{dl}$, HDL-cholesterol $58 \mathrm{mg} / \mathrm{dl}$, LDL-cholesterol $189 \mathrm{mg} / \mathrm{dl}$, and triglycerides $160 \mathrm{mg} / \mathrm{dl}$ ) with normal glucose tolerance (fasting plasma glucose $95 \mathrm{mg} / \mathrm{dl}$ and 2-h post-glucose load $118 \mathrm{mg} / \mathrm{dl}$ ).

\section{Atypical partial lipodystrophy}

Among the individuals with atypical partial lipodystrophy, two of them were found to have mutations in
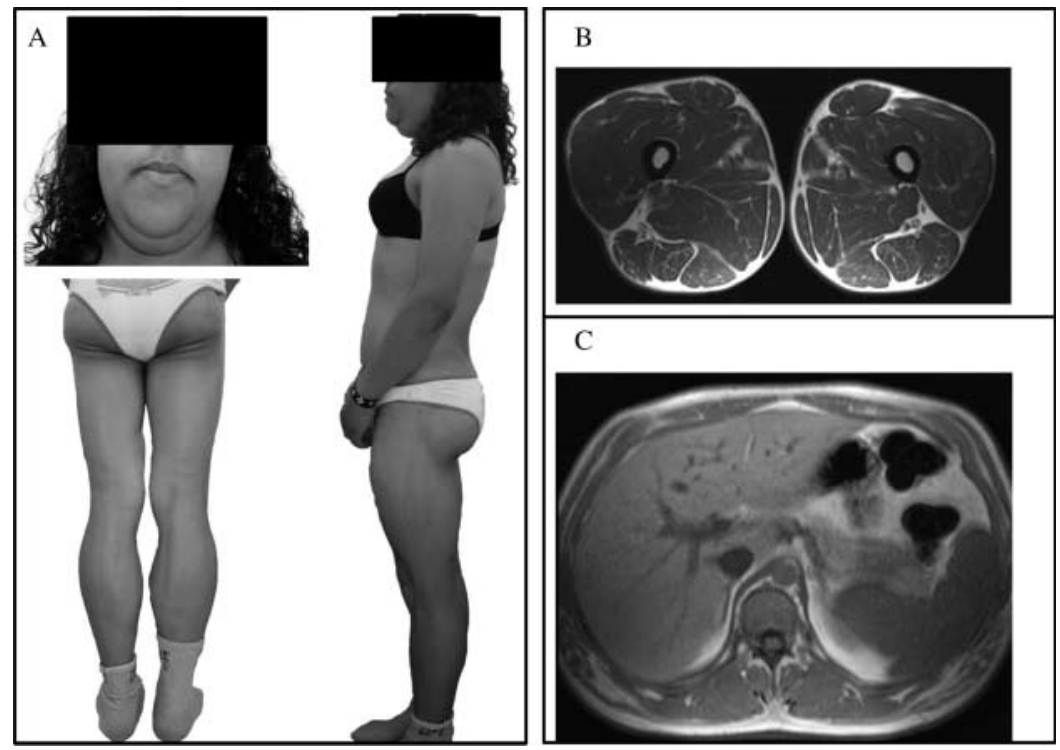

Figure 2 Photograph of P1 with typical FPLD bearing the heterozygous p.N466D LMNA mutation showing the paucity of subcutaneous fat on limbs giving the muscular appearance and the submandibular fat accumulation (A). T1-weighted transaxial magnetic resonance (MR) image at the level of mid-thigh showing loss of subcutaneous fat with preservation of intermuscular and bone marrow fat (B). T1-weighted transaxial abdominal MR image demonstrating increased visceral fat and elevated signal intensity in liver indicating steatosis (C). The patients gave their written consent to the use of their pictures and they understand that complete anonymity cannot be guaranteed. 

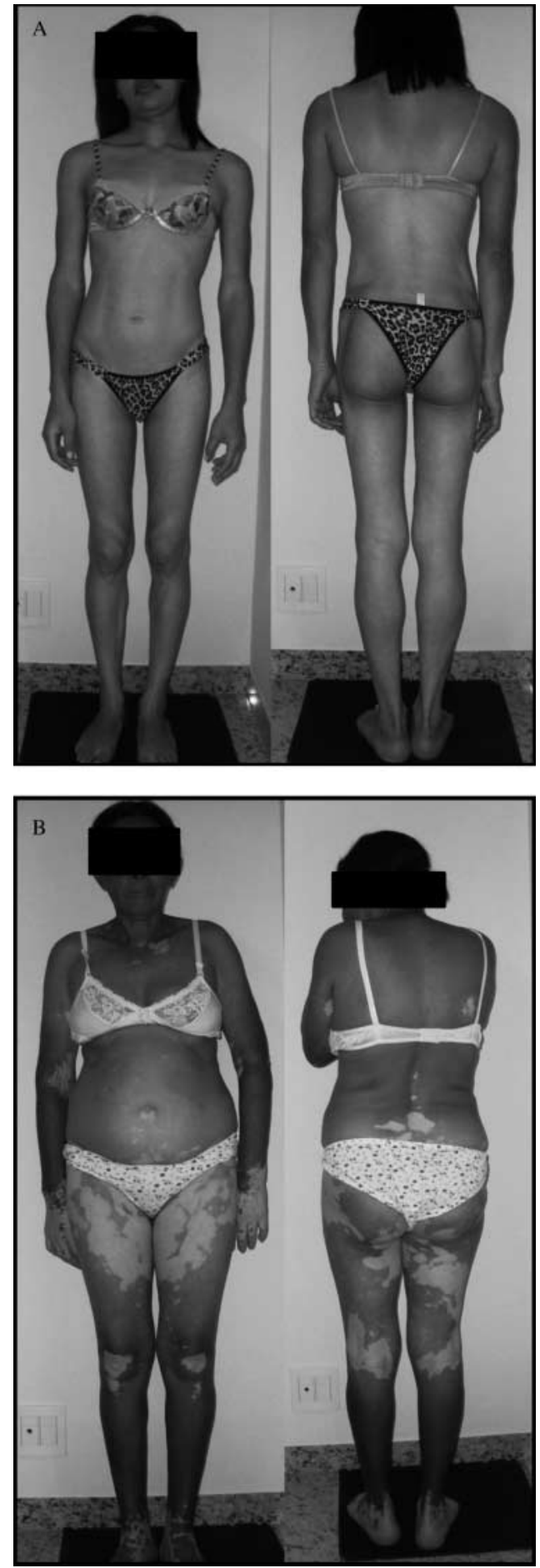

Figure 3 Photograph of P12 with typical FPLD bearing the homozygous p.R584H LMNA mutation, showing decreased subcutaneous fat on limbs and trunk. No submandibular or cervical fat accumulation is observed (A). Photograph of her mother, a heterozygous carrier of p.R584H LMNA mutation showing normal subcutaneous fat distribution and vitiligo's hypochromic skin lesions on face, trunk, and limbs (B). The patients gave their written consent to the use of their pictures and they understand that complete anonymity cannot be guaranteed.
LMNA (P13 and P14). P13 is a 57-year-old woman who has noticed decreased subcutaneous fat on limbs at age 20. Dyslipidemia and hypertension were diagnosed at age 36 and type 2 diabetes at age 43. Physical examination showed moderate decrease in fat in limbs and an increase in upper trunk fat (Fig. 4). She had no acanthosis nigricans. As chronic complications of diabetes, she developed retinopathy, nephropathy, and peripheral neuropathy. A novel heterozygous p.R582C mutation (c.1744 $\mathrm{C}>\mathrm{T}$ ) in exon 11 was found. This variant was not found in 100 normal chromosomes. PolyPhen and SIFT analysis predicts that p.R582C is probably damaging. Patient P14 is an 18-year-old boy with hypertriglyceridemia diagnosed at age 12 during investigation for short stature. Diabetes, hypertension, and acanthosis nigricans were absent. Examination at age 18 revealed loss of subcutaneous fat in limbs including dorsal and palmar aspects of hand and feet and micrognathia (Fig. 5). The age of onset of fat loss was undetermined. Height was $160 \mathrm{~cm}$ (below 5th percentile, both parents were between percentiles 10 and 25). Features of premature ageing such as graying hair, partial alopecia, high-pitched voice, skin atrophy over the hands and feet, bone deformations, and skin pigmentation were absent. Neurological examination showed no evidence of muscle weakness or atrophy, although complaints of myalgia were present. Elevated creatinine phosphokinase (CPK) levels (252 U/l) were observed. Noninvasive cardiac investigation (electrocardiography, transthoracic echocardiography, and 24-h Holter monitoring) was performed and revealed no abnormalities. A heterozygous substitution from arginine for tryptophan at residue 349 (c.1045C $>\mathrm{T}$, p.R349W) in exon 6 was found. Both of his parents were negative for this mutation, indicating that it is a de novo mutation. Figure 6 shows the genealogical trees of families carrying new LMNA mutations demonstrating the familial segregation of the disease.

\section{Generalized lipodystrophy}

LMNA mutation was found in only one patient (P15). Patient P15 with pubertal-onset generalized lipodystrophy and severe insulin resistance was previously described (16). The heterozygous p.T10I (c.29C > T) mutation in exon 1 was found in the proband but was absent in both of her parents. Table 1 shows the main features of patients P1, P11, P12, P13, and P14, and Fig. 7 shows the localization of LMNA mutations identified in the study population.

\section{Discussion}

All our patients with typical FPLD, except the three cases, were found to carry heterozygous mutations affecting codon 482 in exon 8 . This finding confirms previous observations that this residue is a mutational 


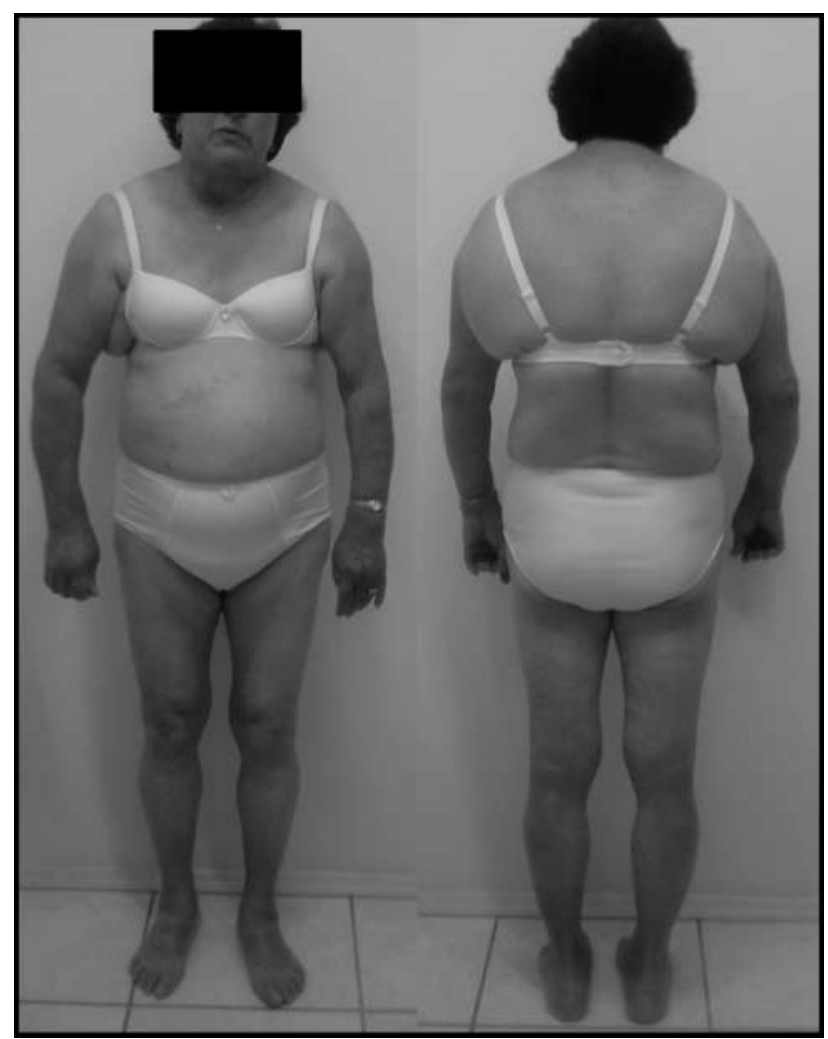

Figure 4 Photograph of P13 with atypical FPLD bearing the heterozygous p.R582C LMNA mutation showing a moderate decrease in subcutaneous fat on legs and an increase in upper trunk fat. No muscular hypertrophy or submandibular fat accumulation is observed. The patients gave their written consent to the use of their pictures and they understand that complete anonymity cannot be guaranteed.

hot spot for $\operatorname{FPLD}(11,23,24)$. A novel mutation (p.N466D), also located in exon 8, was found in two nonrelated patients with typical FPLD. This variant has been already reported in the Leiden Muscular Dystrophy database (http://www.dmd.nl/nmdb/variants.php? action $=$ search_unique\&select_db=LMNA); however, it has not been published elsewhere and there is no clinical information about it. This variant is likely to be pathogenic, as it was absent in 100 control chromosomes, occurs in an amino acid conserved through different species, and segregated with the disease. The two patients affected by this mutation come from distinct states of Brazil and are apparently unrelated, so it is assumed that the mutation has arisen as a separate event. However, additional analysis would be needed to further evaluate a potential founder effect in these families. Another DNA variation we found in a patient with typical partial lipodystrophy was a homozygous p.R584H mutation in exon 11. This patient had only mild metabolic abnormality (low HDL-cholesterol levels and no diabetes or hypertension). The proband's parents were heterozygous for the mutation and had no phenotypic alterations suggestive of lipodystrophy, indicating a recessive trait. Interestingly, two previous reports describing patients with FPLD carriers of this mutation were in heterozygous state and the affected patients showed metabolic complications of lipodystrophy such as diabetes, dyslipidemia, and hepatic steatosis $(24,25)$. To the best of our knowledge, there is only one previous report of a homozygous LMNA mutation associated with a lipodystrophic phenotype (26). Le Dour et al. identified a frameshift mutation and, in contrast to our data, the affected individuals presented a severe lipodystrophy with metabolic alterations. The heterozygous relatives showed either a partial phenotype or were asymptomatic indicating a codominant transmission of the disease with incomplete penetrance in heterozygous subjects. The reasons for these discrepancies are not clear. We can speculate that additional genetic variants and/or intrauterine and postnatal environmental factors might affect the disease expression. Also, the fact that our patient is still young (26 years old) and lean (BMI: $19 \mathrm{~kg} / \mathrm{m}^{2}$ ) could explain her attenuated phenotype. These observations show that lipodystrophy associated with LMNA mutations in exon 11 can be detected in patients presenting a broad clinical spectrum.

Among the patients with atypical partial lipodystrophy, LMNA mutation was found only in two patients. One patient harbors a novel heterozygous CGC $>$ TGC transition at codon 582 (exon 11) leading to an arginine to cysteine substitution (p.R582C). Speckman et al. (23) previously reported a different mutation in the same codon (p.R582H) in a patient with partial lipodystrophy and a detailed evaluation of body fat distribution with anthropometry and magnetic resonance imaging was performed (11). Similarly, as described by theses authors, our patient presented a fat loss from gluteal and truncal regions less pronounced than in patients with the typical phenotype. Mutations in exon 11 affect the globular domain specific to lamin A isoform, while mutations in exon 8 affect the globular domain of both splice forms, lamin A and lamin C. Garg et al. (11) observed a milder lipodystrophy as well as less severe metabolic complications in patients with a mutation in exon 11 of LMNA compared with others with mutations in exon 8. Our findings are in agreement with these observations.

Another patient with atypical lipodystrophy harboring a $L M N A$ mutation was a male subject presenting with fat loss in limbs also involving the palms and soles (mechanical fat loss). This pattern of fat loss drew the attention and permitted the clinical diagnosis of lipodystrophy, as in men this condition is frequently unrecognized. In this patient, the lipodystrophy was not associated with diabetes or hypertension but only with dyslipidemia. Previous reports show that men with FPLD have lower prevalence of metabolic complications of insulin resistance than women $(24,27)$. He was 

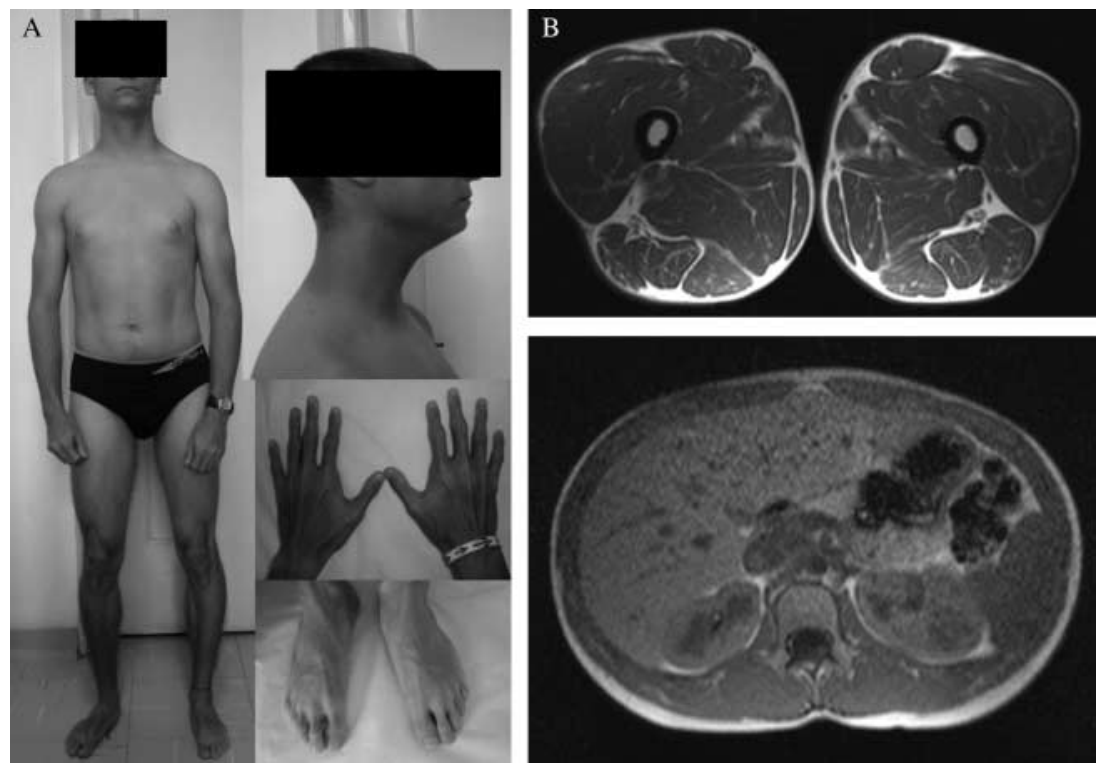

Figure 5 Photograph of P14 with atypical partial lipodystrophy, harboring the heterozygous p.R349W LMNA mutation showing the paucity of subcutaneous fat on limbs including dorsal and palmar aspects of hand and feet, and the presence of micrognathia (A). MR images at the levels of the thigh and abdomen showing markedly reduced subcutaneous fat with preservation of intermuscular and bone marrow fat (B). The patients gave their written consent to the use of their pictures and they understand that complete anonymity cannot be guaranteed. found to carry a heterozygous substitution in a highly conserved residue localized in exon 6 (p.R349W), which affects the $\alpha$-helical rod domain of both lamin $A$ and lamin C. This variant was previously reported in a patient with partial lipodystrophy, mild myopathy, and dilated cardiomyopathy (28). There are other previous reports of $L M N A$ amino-terminal head and $\alpha$-helical rod domain mutations causing overlapping phenotype of partial lipodystrophy and cardiomyopathy or cardiac conduction defects $(29,30)$. Also, at codon 349, another variant (p.R349L) was associated with a severe familial form of isolated dilated cardiomyopathy (31).
In view of these findings, we performed cardiac evaluation of our patient with transthoracic echocardiography and 24-h Holter monitoring, and both were normal. Our observation of this patient shows that p. R349W mutation can, at least at presentation, be associated with lipodystrophy without cardiac abnormality. However, as the patient is still young and in some cases the onset of cardiac manifestations occurred at later ages, a close follow-up was indicated.

Another alteration found was a T10I change in exon 1 in a patient with generalized lipodystrophy. This variation was previously described by Csoka et al. (32) in

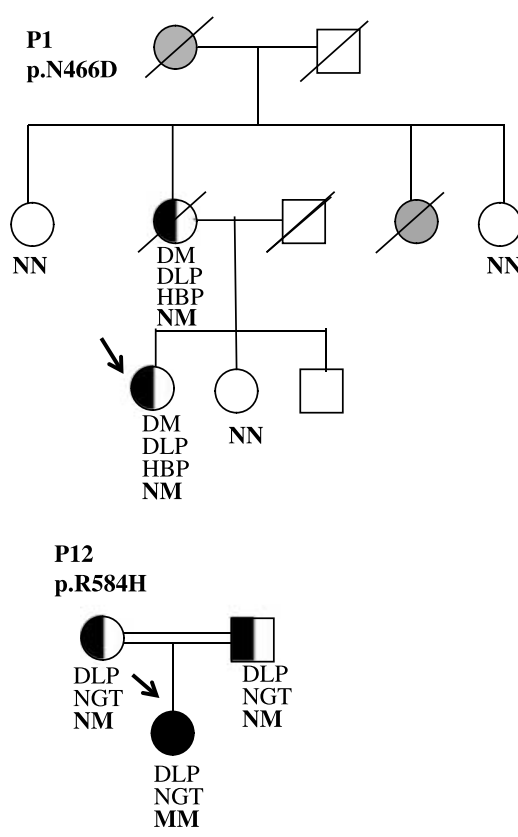

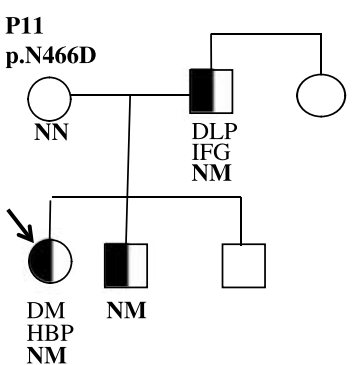

P13

p.R582C

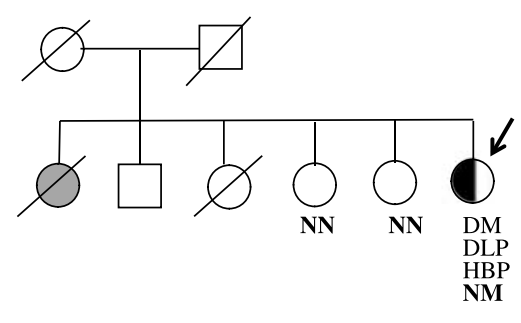

Figure 6 Genealogical trees of families carrying new LMNA mutations. Filled symbols indicate homozygous subjects, half-filled symbols indicate heterozygous subjects, gray symbols indicate subjects probably affected by lipodystrophy, and unfilled symbols indicate individuals unaffected by lipodystrophy. The text below each individual represents the following: DM, diabetes mellitus; IFG, impaired fasting glucose; NGT, normal glucose tolerance; DLP, dyslipidemia; HBP, hypertension; $\mathrm{N}$, wild-type allele; $\mathrm{M}$, mutant allele. 
Table 1 Characteristics of patients $\mathrm{P} 1, \mathrm{P} 11, \mathrm{P} 12, \mathrm{P} 13$, and $\mathrm{P} 14$.

\begin{tabular}{|c|c|c|c|c|c|}
\hline & P1 & P11 & P12 & P13 & P14 \\
\hline LMNA mutation & p.N466D & p.N466D & p.R584H & p.R582C & p.R349W \\
\hline Sex & $\mathrm{F}$ & $\mathrm{F}$ & $\mathrm{F}$ & $\mathrm{F}$ & $\mathrm{M}$ \\
\hline Age (years) & 22 & 19 & 26 & 57 & 18 \\
\hline Lipodystrophy classification & Typical partial & Typical partial & Typical partial & Atypical partial & Atypical partial \\
\hline BMI $\left(\mathrm{kg} / \mathrm{m}^{2}\right)$ & 26 & 28 & 19 & 30 & 20 \\
\hline $\begin{array}{l}\text { Age at diabetes diagnosis } \\
\text { (years) }\end{array}$ & 17 & 18 & - & 43 & - \\
\hline Antidiabetic medications & $\begin{array}{l}\text { MTF, TZD, insulin } \\
0.5 \mathrm{U} / \mathrm{kg} \text { per day }\end{array}$ & MTF & - & $\begin{array}{l}\text { TZD, insulin } 1.4 \mathrm{U} / \mathrm{kg} \\
\text { per day }\end{array}$ & MTF, TZD \\
\hline Acanthosis nigricans & + & + & + & - & - \\
\hline $\begin{array}{l}\text { Antihypertensive } \\
\text { medications }\end{array}$ & ACE inhibitor, HCTZ & ACE inhibitor & - & $\begin{array}{l}\text { ACE inhibitor, } \\
\text { furosemide, } \mathrm{CCB}\end{array}$ & - \\
\hline Lipid lowering medications & - & - & - & Statin & Statin, fibrate \\
\hline Other features & Thyroid nodule & - & Thyroid nodule & $\begin{array}{l}\text { Arrhythmia, depression, } \\
\text { thyroiditis }\end{array}$ & Myalgia \\
\hline $\mathrm{HbA1c}(\%)$ & 11.7 & 6.9 & ND & 9.6 & 5.9 \\
\hline HOMA-IR & ND & 31.1 & 1.3 & ND & 5.9 \\
\hline Adiponectin (ng/ml) & 4.8 & 4.5 & 5.2 & 18.0 & $<0.2$ \\
\hline Leptin $(\mu \mathrm{g} / \mathrm{ml})$ & 6.0 & 4.6 & 1.1 & 32.9 & 2.2 \\
\hline Total-cholesterol (mg/dl) & 155 & 185 & 145 & 170 & 150 \\
\hline HDL-cholesterol (mg/dl) & 29 & 41 & 46 & 42 & 17 \\
\hline LDL-cholesterol (mg/dl) & ND & 113 & 61 & 100 & 91 \\
\hline Triglycerides $(\mathrm{mg} / \mathrm{dl})$ & 544 & 157 & 125 & 156 & 210 \\
\hline AST $(U / I)$ & 15 & 13 & 11 & 18 & 18 \\
\hline $\operatorname{ALT}(\mathrm{U} / \mathrm{I})$ & 27 & 21 & 16 & 17 & 21 \\
\hline CPK (U/I) & 92 & ND & ND & 60 & 252 \\
\hline Hepatic steatosis & + & ND & - & + & ND \\
\hline Total body fat (\%) & 20.7 & 14.1 & 12.1 & 34.6 & 14.2 \\
\hline Trunk fat (\%) & 23.2 & 17.3 & 13.7 & 43.5 & 16.7 \\
\hline Arms fat (\%) & 19.1 & 12.6 & 7.5 & 34.5 & 14.3 \\
\hline Legs fat (\%) & 16.3 & 10.7 & 12.0 & 20.7 & 10.9 \\
\hline
\end{tabular}

ACE, angiotensin-converting enzyme; CCB, calcium channel blocker; HCTZ, hydrochlorothiazide; MTF, metformin; ND, not determined; TZD, thiazolidinedione.

a patient diagnosed with atypical progeroid syndrome, later reclassified as 'Seip syndrome' based on generalized lipoatrophy and metabolic alterations. Complex genotype-phenotype relationships are present in laminopathies, and variability in the lipodystrophy clinical expression in patients, even among family members, with the same mutation has been reported previously $(25,33)$. Nongenetic factors and/or additional genetic variants may modulate the disease phenotype.

In this study, we found seven different LMNA mutations in patients with various forms of lipodystrophy, most of them $(5 / 7)$ in region $3^{\prime}$ to the nuclear localization signal sequence (codons 416-423). Hegele using hierarchical cluster analysis for assembling laminopathies according to phenotypic similarity found that LMNA mutations at the $5^{\prime}$ of codon 416 were seen more frequently in laminopathies with cardiac or neurological involvement, and in addition several overlapping syndromes, while mutations at the $3^{\prime}$ of codon 423 are more likely to be associated with simple partial lipodystrophy, progeria syndrome, or mandibuloacral dysplasia (34). Our findings are in agreement with this, as the mutations found at the $3^{\prime}$ to the nuclear localization signal were in patients with simple partial lipodystrophy. The two mutations found at the $5^{\prime}$ to the nuclear localization signal were in

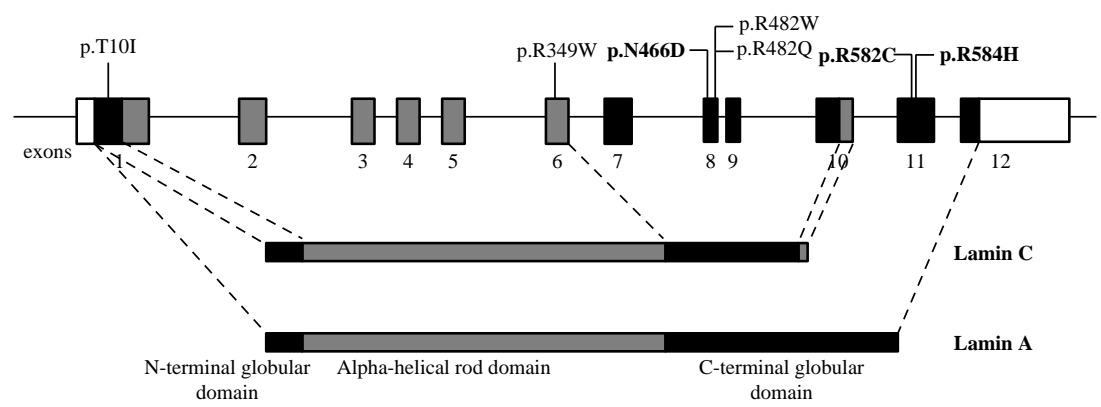

Figure $7 L M N A$ mutations identified in the study population and their relation to the gene and protein structure of lamins A and $\mathrm{C}$. Novel mutations are shown in bold. 
patients with complex overlapping syndromes. Although no cardiac or neurological involvement was present in the affected subjects, we cannot exclude the possibility that these conditions appear later in life as these patients are still young.

A limitation of our study is that our data only concern LMNA-linked lipodystrophies. Besides LMNA, several other loci (i.e. PPARG, AKT2, CAV1, CIDEC, and PLIN1) have been implicated in the pathogenic basis of lipodystrophic syndromes $(35,36,37,38,39)$. Therefore, additional sequencing for these loci could be considered in our patients with no LMNA mutations.

In summary, we have identified LMNA mutations in phenotypically diverse, either partial or generalized, lipodystrophies. Also, novel mutations were found, broadening the spectrum of reported genotypes in lipodystrophy, and variable phenotypes associated with previously reported mutations have been identified.

\section{Declaration of interest}

The authors declare that there is no conflict of interest that could be perceived as prejudicing the impartiality of the research reported.

\section{Funding}

This study was supported by Fundação de Amparo à Pesquisa do Estado de São Paulo (FAPESP, grant \# 07/59297-1).

\section{Acknowledgements}

The authors are grateful to the patients and their families for participating in the study and to Dr Amanda O Silveira for patient referral.

\section{References}

1 Lin F \& Worman HJ. Structural organization of the human gene encoding nuclear lamin A and nuclear lamin C. Journal of Biological Chemistry 1993268 16321-16326.

2 Worman HJ, Fong LG, Muchir A \& Young SG. Laminopathies and the long strange trip from basic cell biology to therapy. Journal of Clinical Investigation 2009119 1825-1836. (doi:10.1172/ JCI37679)

3 Bonne G, Di Barletta MR, Varnous S, Becane HM, Hammouda EH, Merlini L, Muntoni F, Greenberg CR, Gary F, Urtizberea JA, Duboc D, Fardeau M, Toniolo D \& Schwartz K. Mutations in the gene encoding lamin A/C cause autosomal dominant EmeryDreifuss muscular dystrophy. Nature Genetics 199921 285-288. (doi:10.1038/6799)

4 Muchir A, Bonne G, van der Kooi AJ, van Meegen M, Baas F, Bolhuis PA, de Visser M \& Schwartz K. Identification of mutations in the gene encoding lamins $\mathrm{A} / \mathrm{C}$ in autosomal dominant limb girdle muscular dystrophy with atrioventricular conduction disturbances (LGMD1B). Human Molecular Genetics 20009 1453-1459. (doi:10.1093/hmg/9.9.1453)

5 Fatkin D, MacRae C, Sasaki T, Wolff MR, Porcu M, Frenneaux M, Atherton J, Vidaillet HJ, Spudich S, De Girolami U, Seidman JG \& Seidman CE. Missense mutations in the rod domain of the lamin $\mathrm{A} / \mathrm{C}$ gene as causes of dilated cardiomyopathy and conduction-system disease. New England Journal of Medicine 1999341 1715-1724. (doi:10.1056/NEJM199912023412302)
6 De Sandre-Giovannoli A, Chaouch M, Kozlov S, Vallat JM, Tazir M, Kassouri N, Szepetowski P, Hammadouche T, Vandenberghe A, Stewart CL, Grid D \& Lévy N. Homozygous defects in LMNA, encoding lamin A/C nuclear-envelope proteins, cause autosomal recessive axonal neuropathy in human (Charcot-Marie-Tooth disorder type 2) and mouse. American Journal of Human Genetics 200270 726-736. (doi:10.1086/339274)

7 Eriksson M, Brown WT, Gordon LB, Glynn MW, Singer J, Scott L, Erdos MR, Robbins CM, Moses TY, Berglund P, Dutra A, Pak E, Durkin S, Csoka AB, Boehnke M, Glover TW \& Collins FS. Recurrent de novo point mutations in lamin A cause HutchinsonGilford progeria syndrome. Nature $2003 \mathbf{4 2 3}$ 293-298. (doi:10. 1038/nature01629)

8 Shackleton S, Lloyd DJ, Jackson SNJ, Evans R, Niermeijer MF, Singh BM, Schmidt H, Brabant G, Kumar S, Durrington PN, Gregory S, O'Rahilly S \& Trembath RC. LMNA, encoding lamin A/C, is mutated in partial lipodystrophy. Nature Genetics 200024 153-156. (doi:10.1038/72807)

9 Garg A. Acquired and inherited lipodystrophies. New England Journal of Medicine $2004 \mathbf{3 5 0}$ 1220-1234. (doi:10.1056/ NEJMra025261)

10 Agarwal AK \& Garg A. Genetic basis of lipodystrophies and management of metabolic complications. Annual Review of Medicine 200657 297-311. (doi:10.1146/annurev.med.57. 022605.114424)

11 Garg A, Vinaitheerthan M, Weatherall PT \& Bowcock AM. Phenotypic heterogeneity in patients with familial partial lipodystrophy (Dunnigan variety) related to the site of missense mutations in lamin A/C gene. Journal of Clinical Endocrinology and Metabolism 200186 59-65. (doi:10.1210/jc.86.1.59)

12 Savage DB, Soos MA, Powlson A, O'Rahilly S, McFarlane I, Halsall DJ, Barroso I, Thomas EL, Bell JD, Scobie I, Belchetz PE, Kelly WF \& Schafer AJ. Familial partial lipodystrophy associated with compound heterozygosity for novel mutations in the LMNA gene. Diabetologia 200447 753-756. (doi:10.1007/s00125-0041360-4)

13 Decaudain A, Vantyghem MC, Guerci B, Hécart AC, Auclair M, Reznik Y, Narbonne H, Ducluzeau PH, Donadille B, Lebbé C, Béréziat V, Capeau J, Lascols O \& Vigouroux C. New metabolic phenotypes in laminopathies: LMNA mutations in patients with severe metabolic syndrome. Journal of Clinical Endocrinology and Metabolism 200792 4835-4844. (doi:10.1210/jc.2007-0654)

14 Chen L, Lee L, Kudlow BA, Dos Santos HG, Sletvold O, Shafeghati Y, Botha EG, Garg A, Hanson NB, Martin GM, Mian IS, Kennedy BK \& Oshima J. LMNA mutations in atypical Werner's syndrome. Lancet $2003 \mathbf{3 6 2} 440-445$. (doi:10.1016/ S0140-6736(03)14069-X)

15 Caux F, Dubosclard E, Lascols O, Buendia B, Chazouillères O, Cohen A, Courvalin JC, Laroche L, Capeau J, Vigouroux C \& Christin-Maitre S. A new clinical condition linked to a novel mutation in lamins A and C with generalized lipoatrophy, insulinresistant diabetes, disseminated leukomelanodermic papules, liver steatosis, and cardiomyopathy. Journal of Clinical Endocrinology and Metabolism $2003 \mathbf{8 8}$ 1006-1013. (doi:10.1210/jc.2002021506)

16 Mory PB, Crispim F, Kasamatsu T, Gabbay MA, Dib SA \& Moisés RS. Atypical generalized lipoatrophy and severe insulin resistance due to a heterozygous LMNA p.T10I mutation. Arquivos Brasileiros de Endocrinologia e Metabologia 200852 1251-1255. (doi:10.1590/S0004-27302008000800008)

17 Garg A, Subramanyam L, Agarwal AK, Simha V, Levine B, D’Apice MR, Novelli G \& Crow Y. Atypical progeroid syndrome due to heterozygous missense LMNA mutations. Journal of Clinical Endocrinology and Metabolism 200994 4971-4983. (doi:10.1210/jc.2009-0472)

18 Genuth S, Alberti KG, Bennett P, Buse J, Defronzo R, Kahn R, Kitzmiller J, Knowler WC, Lebovitz H, Lernmark A, Nathan D, Palmer J, Rizza R, Saudek C, Shaw J, Steffes M, Stern M, Tuomilehto J, Zimmet P \& Expert Committee on the Diagnosis 
and Classification of Diabetes Mellitus. Follow-up report on the diagnosis of diabetes mellitus. Diabetes Care 200326 3160-3167. (doi:10.2337/diacare.26.12.3331)

19 Expert Panel on Detection, Evaluation, and Treatment of High Blood Cholesterol in Adults. Executive Summary of the Third Report of the National Cholesterol Education Program (NCEP) Expert Panel on Detection, Evaluation, and Treatment of High Blood Cholesterol In Adults (Adult Treatment Panel III). Journal of the American Medical Association 2001285 2486-2497. (doi:10.1001/jama.285.19.2486)

20 Chobanian AV, Bakris GL, Black HR, Cushman WC, Green LA, Izzo JL Jr, Jones DW, Materson BJ, Oparil S, Wright JT Jr, Roccella EJ \& National Heart, Lung, and Blood Institute Joint National Committee on Prevention, Detection, Evaluation, and Treatment of High Blood Pressure \& National High Blood Pressure Education Program Coordinating Committee. The Seventh Report of the Joint National Committee on Prevention, Detection, Evaluation, and Treatment of High Blood Pressure: the JNC 7 report. Journal of the American Medical Association 2003289 2560-2672. (doi:10. 1001/jama.289.19.2560)

21 Sunyaev S, Ramensky V, Koch I, Lathe W III, Kondrashov AS \& Bork P. Prediction of deleterious human alleles. Human Molecular Genetics 200110 591-597. (doi:10.1093/hmg/10.6.591)

$22 \mathrm{Ng} \mathrm{PC} \mathrm{\&} \mathrm{Henikoff} \mathrm{S.} \mathrm{SIFT:} \mathrm{predicting} \mathrm{amino} \mathrm{acid} \mathrm{changes}$ that affect protein function. Nucleic Acids Research $2003 \mathbf{3 1}$ 3812-3814. (doi:10.1093/nar/gkg509)

23 Speckman RA, Garg A, Du F, Bennett L, Veile R, Arioglu E, Taylor SI, Lovett M \& Bowcock AM. Mutational and haplotype analyses of families with familial partial lipodystrophy (Dunnigan variety) reveal recurrent missense mutations in the globular C-terminal domain of lamin A/C. American Journal of Human Genetics 200066 1192-1198. (doi:10.1086/302836)

24 Vigouroux C, Magré J, Vantyghem MC, Bourut C, Lascols O, Shackleton S, Lloyd DJ, Guerci B, Padova G, Valensi P, Grimaldi A, Piquemal R, Touraine P, Trembath RC \& Capeau J. Lamin A/C gene: sex-determined expression of mutations in Dunnigan-type familial partial lipodystrophy and absence of coding mutations in congenital and acquired generalized lipoatrophy. Diabetes 2000 49 1958-1962. (doi:10.2337/diabetes.49.11.1958)

25 Hegele RA, Cao H, Anderson CM \& Hramiak IM. Heterogeneity of nuclear lamin A mutations in Dunnigan-type familial partial lipodystrophy. Journal of Clinical Endocrinology and Metabolism 200085 3431-3435. (doi:10.1210/jc.85.9.3431)

26 Le Dour C, Schneebeli S, Bakiri F, Darcel F, Jacquemont ML, Maubert MA, Auclair M, Jeziorowska D, Reznik Y, Béréziat V, Capeau J, Lascols O \& Vigouroux C. A homozygous mutation of Prelamin-A preventing its farnesylation and maturation leads to a severe lipodystrophic phenotype: new insights into the pathogenicity of nonfarnesylated Prelamin-A. Journal of Clinical Endocrinology and Metabolism 201196 E856-E862. (doi:10.1210/jc.2010-2234)

27 Garg A. Gender differences in the prevalence of metabolic complications in familial lipodystrophy (Dunnigan variety). Journal of Clinical Endocrinology and Metabolism $2000 \mathbf{8 5}$ 1776-1782. (doi:10.1210/jc.85.5.1776)

28 van Tintelen JP, Hofstra RM, Katerberg H, Rossenbacker T, Wiesfeld AC, du Marchie Sarvaas GJ, Wilde AA, van Langen IM, Nannenberg EA, van der Kooi AJ, Kraak M, van Gelder IC, van Veldhuisen DJ, Vos Y \& van den Berg MP. High yield of LMNA mutations in patients with dilated cardiomyopathy and/or conduction disease referred to cardiogenetics outpatient clinics. American Heart Journal 2007154 1130-1139. (doi:10.1016/ j.ahj.2007.07.038)

29 Garg A, Speckman RA \& Bowcock AM. Multisystem dystrophy syndrome due to novel missense mutations in the amino-terminal head and $\alpha$-helical rod domains of the lamin A/C gene. American Journal of Medicine 2002112 549-555. (doi:10.1016/SOOO29343(02)01070-7)

30 Subramanyam L, Simha V \& Garg A. Overlapping syndrome with familial partial lipodystrophy, Dunnigan variety and cardiomyopathy due to amino-terminal heterozygous missense lamin $\mathrm{A} / \mathrm{C}$ mutations. Clinical Genetics 201078 66-73. (doi:10.1111/j. 1399-0004.2009.01350.x)

31 Hermida-Prieto M, Monserrat L, Castro-Beiras A, Laredo R, Soler R, Peteiro J, Rodríguez E, Bouzas B, Alvarez N, Muñiz J \& Crespo-Leiro M. Familial dilated cardiomyopathy and isolated left ventricular noncompaction associated with lamin $\mathrm{A} / \mathrm{C}$ gene mutations. American Journal of Cardiology 200494 50-54. (doi:10.1016/j.amjcard.2004.03.029)

32 Csoka AB, Cao H, Sammak PJ, Constantinescu D, Schatten GP \& Hegele RA. Novel lamin A/C gene (LMNA) mutations in atypical progeroid syndromes. Journal of Medical Genetics $2004 \mathbf{4 1}$ 304-308. (doi:10.1136/jmg.2003.015651)

33 Rankin J, Auer-Grumbach M, Bagg W, Colclough K, Nguyen TD, Fenton-May J, Hattersley A, Hudson J, Jardine P, Josifova D, Longman C, McWilliam R, Owen K, Walker M, Wehnert M \& Ellard S. Extreme phenotypic diversity and nonpenetrance in families with the LMNA gene mutation R644C. American Journal of Medical Genetics 2008 146A 1530-1542. (doi:10.1002/ajmg.a. 32331)

34 Hegele RA. LMNA mutation position predicts organ system involvement in laminopathies. Clinical Genetics 200568 31-34. (doi:10.1111/j.1399-0004.2005.00447.x)

35 Agarwal AK \& Garg A. A novel heterozygous mutation in peroxisome proliferatoractivated receptor- $\gamma$ gene in a patient with familial partial lipodystrophy. Journal of Clinical Endocrinology and Metabolism 200287 408-411. (doi:10.1210/jc.87.1.408)

36 George S, Rochford JJ, Wolfrum C, Gray SL, Schinner S, Wilson JC, Soos MA, Murgatroyd PR, Williams RM, Acerini CL, Dunger DB, Barford D, Umpleby AM, Wareham NJ, Davies HA, Schafer AJ, Stoffel M, O'Rahilly S \& Barroso I. A family with severe insulin resistance and diabetes due to a mutation in AKT2. Science 2004 304 1325-1328. (doi:10.1126/science.1096706)

37 Cao H, Alston L, Ruschman J \& Hegele RA. Heterozygous CAV1 frameshift mutations (MIM 601047) in patients with atypical partial lipodystrophy and hypertriglyceridemia. Lipids in Health and Disease 20087 3. (doi:10.1186/1476-511X-7-3)

38 Rubio-Cabezas O, Puri V, Murano I, Saudek V, Semple RK, Dash S, Hyden CS, Bottomley W, Vigouroux C, Magré J, Raymond-Barker P, Murgatroyd PR, Chawla A, Skepper JN, Chatterjee VK, Suliman S, Patch AM, Agarwal AK, Garg A, Barroso I, Cinti S, Czech MP, Argente J, O'Rahilly S, Savage DB \& LD Screening Consortium. Partial lipodystrophy and insulin resistant diabetes in a patient with a homozygous nonsense mutation in CIDEC. EMBO Molecular Medicine 20091 280-287. (doi:10.1002/emmm. 200900037)

39 Gandotra S, Le Dour C, Bottomley W, Cervera P, Giral P, Reznik Y, Charpentier G, Auclair M, Delépine M, Barroso I, Semple RK, Lathrop M, Lascols O, Capeau J, O'Rahilly S, Magré J, Savage DB \& Vigouroux C. Perilipin deficiency and autosomal dominant partial lipodystrophy. New England Journal of Medicine 2011364 740-748. (doi:10.1056/NEJMoa1007487)

Received 29 October 2011

Revised version received 9 May 2012

Accepted 14 June 2012 